\title{
Inscripciones celtibéricas con fórmula de filiación onomástica expresa
}

\author{
Serafín Olcoz Yanguas y Manuel Medrano Marqués \\ Universidad de Zaragoza \\ solcoz@gmail.com y medrano@unizar.es
}

Celtiberian inscriptions containing express onomastic filiation formulae

Revisión paleográfica y posible nueva lectura de tres inscripciones que presentan expresiones de filiación: una tésera celtibérica de La Custodia (Viana), la estela de Langa de Duero (Soria, Castilla y León) y otra tésera que también podría haber sido hallada en Viana. Con esta revisión se completa el estudio de las inscripciones paleohispánicas con filiación expresa en su fórmula de onomástica celtibérica que, ahora, se extendería a una novena, al menos.

Palabras clave: Semisilabario celtibérico; expresión de filiación; paleografía.
Palaeographical review and possible new reading of three inscriptions with expressions of filiation: a Celtiberian tessera of La Custodia (Viana), the stela of Langa de Duero (Soria, Castilla y León) and another tessera that could also came from Viana. With this revision, the study of Palaeohispanic inscriptions with expressed filiation in its formula of Celtiberian onomastics is completed that, now, would extend at least to a ninth.

Keywords: Celtiberian semi-syllabary; expression of filiation; palaeography.

\section{Introducción}

Tal y como recordó Untermann, citando a Tovar, la fórmula de denominación de los nombres personales u onomástica típica en el territorio celtibérico se puede describir como

la denominación que se compone del nombre individual de la persona nombrada, del nombre individual del padre en genitivo y de la palabra para «hijo» (por tanto, en ropaje latino f. = filius) y de una designación de grupo señalada sufijalmente en genitivo plural ${ }^{1}$.

\footnotetext{
${ }^{1}$ Untermann 2000, p. 126, cf. Tovar 1949, pp. 97-114.
} 
La generalizada suposición de que la presencia de un signo ke puede corresponder a la abreviatura de kentis y que esta palabra se podría interpretar como 'hijo de' llevó a varios lingüistas a recopilar el conjunto de breves inscripciones en las que se apreciaba la filiación expresa en su fórmula de onomástica celtibérica ${ }^{2}$, sin contar con la posibilidad de que esta relación también pueda figurar en el primer bronce de Contrebia Belaisca (Botorrita, Zaragoza) (K.1.1) ${ }^{3}$, por ejemplo ${ }^{4}$.

Por otra parte, al avanzar en la revisión paleográfica de las inscripciones celtibéricas que estamos realizando, nos hemos encontrado con que la lectura de tres de ellas, a pesar de ser conocidas hace muchos años, aún era incompleta y que, además, también hacía mucho tiempo que no se había avanzado en su discernimiento. Encontrándose la primera de éstas en una de las cuatro téseras de hospitalidad procedentes del yacimiento arqueológico de La

${ }^{2}$ Untermann, en el citado trabajo, en su versión previa y su clasificación de inscripciones celtibéricas (1967, pp. 283-285, 1997, p. 509, y 2000, pp. 126, 128 y 138), interpretó ke como abreviatura de kentis, con significado de 'hijo de', en las inscripciones celtibéricas realizadas en signario paleohispánico K.0.2, K.16.1, K.17.1, así como $G$ en las escritas en alfabeto latino K.3.14 y K.26.1 (figs. 1-5). Actualmente esta interpretación es generalizada, como recogió Jordán 2004, pp. 170-171, 222, 264 y 280, señalando que no es uniforme ya que, por ejemplo, también fue admitida aunque con reservas por Beltrán y De Hoz (De Hoz 1986, p. 90, y Beltrán, De Hoz y Untermann 1996, p. 58), que consideraron la correspondencia de ke o kentis con "'hijo' o algo similar, sin olvidar su homofonía con el término gens que en las inscripciones latinas designa con frecuencia al grupo familiar hispano-céltico». También considerado por Olcoz y Medrano e. p.

3 Untermann 1997, pp. 576-606.

${ }^{4}$ Hay que señalar que Jordán 2007, pp. 131 y 339-340, corrigió recientemente la lectura del grafito numantino K.9.5 (Gómez 1949, p. 312, Untermann 1997, pp. 668-669, y Jordán 2004, pp. 176 y 339-340), que se venía leyendo como arebasikoo[ / $s+$ [, como arebalbiiko +[ $/ s+[$, con lo que introdujo una posible redundancia vocálica no sistemática. Sin embargo, aunque creemos que esta revisión paleográfica es correcta, también hemos planteado la posibilidad de que no presentaría esta anomalía si su interpretación fuera arebalkeiko $+\left[/ s^{+}\right.$, siguiendo la propuesta que hiciera Velaza 1999, pp. 675-676, para interpretar el signo cuya morfología se parece gráficamente al del griego П como si fuera una variante de $k e$, en lugar de hacerlo serlo de bi. Con lo que obtenía la lectura kentis, en vez de bintis, en la inscripción de la cara B de K.1.1, confirmando una relación que ya había intuido De Hoz 1986, p. 90. Aunque últimamente venía siendo cuestionada por Prósper 2007, pp. 51-54, y 2008, pp. 1518, parece que, de alguna manera, ésta lo viene reconsiderando. Por lo que, de confirmarse la recuperación de esta lectura, también habría que incluir las 14 citas de K.1.1 entre las inscripciones en las que se apreciaba la filiación expresa en su fórmula onomástica celtibérica. También considerado por Olcoz y Medrano e. p. 
Custodia (Viana) que fueron halladas casualmente, poco antes de 1987, por Labeaga ${ }^{5}$. La segunda inscripción paleohispánica en cuestión se encuentra en una estela que fue hallada en 1928 por Taracena en las excavaciones arqueológicas que llevó a cabo en Langa de Duero (Soria) ${ }^{6}$. Finalmente, la tercera es una de las dos téseras de hospitalidad que pertenecen o, mejor dicho, pertenecieron a la colección del anticuario Rainer Daehnhardt, afincado en Portugal, y que fueron dadas a conocer por Faria en 1998 (CD-1) ${ }^{7}$. Quien señaló que, aunque se desconocía su origen, quizá ambas procedían también de La Custodia, dado el parecido de la primera de ellas en forma, diseño y dimensiones con la que contiene la inscripción berkuakum (:) sakas $(\mathrm{K} .18 .1)^{8}$, que también fue realizada en la variante oriental del celtibérico. Aunque, en este último caso, la técnica empleada fue batir un punzón en cuyo extremo había dos puntas que simulaban el punteado (fig. 6), en vez de un punzón de afilada punta con la que marcar cada punto o esgrafiar el trazo correspondiente.

${ }^{5}$ El poblado del yacimiento de La Custodia se encuentra cerca de los actuales límites entre Navarra, La Rioja y el País Vasco, en la margen izquierda del Ebro, y presenta restos correspondientes al largo período de tiempo que va desde el neolítico al comienzo de la romanización. Fue destruido poco antes del cambio de era, aunque también se han hallado algunos restos de las primeras décadas del siglo I d. C., previos a su definitiva destrucción y abandono. Acontecimiento que se ha puesto en relación con la fundación, al otro lado del Ebro, de la Vareia romana (Varea-Logroño), junto a la desembocadura de su afluente, el Iregua (Castiella 1976, p. 239, Labeaga 1987, pp. 459 y 463, Labeaga y Untermann 1993-1994, pp. 45 y 49, y Labeaga 1999-2000). Se ha propuesto la identificación de este yacimiento con la ciudad y ceca berona de uarakos, a pesar de que no hay duda de que ésta estuvo situada, al menos, en la cima del cercano Monte Cantabria (Logroño) y que es posible que, por tanto, el yacimiento de La Custodia corresponda a la parte no fortificada de esta ciudad berona (Armendáriz 1997-1998) o a la ciudad y ceca vascona de barskunez, cuyas monedas son las que con mayor abundancia se han encontrado en este yacimiento (Burillo 1995, p. 176, García-Bellido y Blázquez 2001, pp. 55-57 y 383-384, y Olcoz y Medrano 2006, p. 62).

${ }^{6}$ Taracena 1929, pp. 31-32 y 50-52, propuso la ubicación de la ceca de sekotiaz lakaz y ciudad arévaca y romana de Segontia Langa en el yacimiento arqueológico ubicado desde el altozano de Las Quintanas (Langa de Duero) hasta el de La Cuesta del Moro (Langa de Duero), lugar este último en el que fue hallada la citada estela con la inscripción celtibérica, formando parte de las piedras con las que se había construido una de las majadas que allí había. Propuesta de ubicación por la que también se decantan García-Bellido y Blázquez 2001, p. 348. La cronología del yacimiento arqueológico va desde mediados del siglo II a. C. hasta la primera mitad del I a. C., pudiendo ser completamente abandonada en torno al cambio de era (Tabernero, Heras, Benito y Sanz 2005, pp. 197, 199, 202-203).

7 Faria 1998, pp. 120-121.

${ }^{8}$ Labeaga 1987, pp. 458-459 y 463, Velaza 1989, pp. 193-195. 
A continuación presentamos el resultado de la revisión paleográfica de estas tres inscripciones que han pasado a engrosar el pequeño conjunto de los textos paleohispánicos con filiación expresa en su fórmula onomástica celtibérica que, de paso, también revisamos?.

\section{Revisión y lectura completa de la inscripción K.18.2}

La incompleta lectura de la tésera de hospitalidad que tiene forma de cuartos traseros de un bóvido, cuya inscripción fue realizada mediante la técnica de incisión continua y que está fechada entre las primeras décadas del siglo II y la mitad del I a. C. ${ }^{10}$, se ha venido estableciendo como ]+iko:loukio:kete[ / ]ko[. Seguramente ha sido así porque se pensaba que faltaba parte de la inscripción. Bien porque se consideraba que se habría perdido debido al desgaste de la pieza o porque quizá se encontrara en la parte superior del bóvido y correspondería a la otra mitad de la tésera que no se ha localizado (ni tampoco hay constancia de que hubiera existido), K.18.02 ${ }^{11}$.

${ }^{9}$ Debemos enmendar la lectura que presentamos acerca de la tésera de hospitalidad procedente de la colección de Max Turiel pero de origen desconocido, CT-23A (cf. Untermann 1997, pp. 652-657, y Jordán 2004, pp. 250-255 y 312-319), cuya lectura realizamos a partir de la copia de la fotografía adquirida en la Real Academia de la Historia, como kariko (:) kaiaikunos / arkailika / kar, para asumir parte de la lectura que realizó Jordán, aunque sin encontrar ningún problema en arkailika, y decantándonos (Olcoz y Medrano 2005-2007, pp. 208-210) por kariko en vez de kateiko (fig. 7), como ya propusiera Ballester 2004, pp. 272-273, y también recogiera Jordán como alternativa por la que no acabó decantándose. Almagro 2003, pp. 377-379, había establecido la relación de kariko con karikokue, en la tésera de hospitalidad de Luzaga (K.6.1), que, sin razón, fue cuestionada por Ballester, aunque a éste le corrigió después sobre este punto Jordán. No obstante, Ballester aportó paralelos con CARICOQ de Coca (Segovia) y otras formas afines que habían sido recogidas por Villar y Jordán (Villar, Díaz, Medrano y Jordán 2001, pp. 159, 162 y 181), a los que este último añadió el de CARICVS, citado en CIL II 899 (Talavera de la Reina) y CIL II 2954 (Contrasta), como «paralelo perfecto». Además, Jordán 2007, pp. 105-106, propuso que, de acuerdo con el sistema de escritura dual con el que sería coherente, debería leerse como gariko (:) kamaikuno (:) ke / argailika / kar. Aunque también precisó que la lectura de ke estaría en contradicción con la etimología GENTIS. Por lo que su interpretación sería «De Garicos, hijo de Camaicunos / amistad de (UXAMA) ARGAELA». Nuevamente, agradecemos a Martín Almagro-Gorbea que nos facilitara la adquisición de la fotografía de esta tésera de hospitalidad que se conserva en la Real Academia de la Historia y que es la única información conocida acerca de esta pieza.

${ }_{10}$ Velaza 1989, p. 197.

${ }^{11}$ Además, Jordán consideró el texto de esta tésera de hospitalidad (cf. Untermann 1997, pp. 698-699), debido a que «la dificultad de lectura, la falta de contraste gráfico y la de apoyos 
La información que podía ofrecer este texto para los lingüistas e incluso para los arqueólogos e historiadores era mínima o casi nula, de ahí que nos decidiéramos a realizar la revisión paleográfica que presentamos a continuación.

El caso es que, dejando al margen esa posibilidad y centrándonos en la simple observación detallada de esta inscripción, hemos podido constatar que está completa y que las dificultades halladas para su lectura se debían a que quienes lo habían intentado no habían considerado que había sido realizada de forma periférica y girando su escritura en espiral, alrededor del borde del objeto $^{12}$. Hecho esto, hemos podido identificar las tres palabras que la componen y que están separadas cada una de ellas por una interpunción doble y alineada verticalmente, así como por una simple que está ubicada al final de la inscripción ${ }^{13}$. Lo que nos ha llevado a proponer la lectura espiral tekoniko (:) loukio (:) $\mathrm{ke}^{14}$ (.), considerando que la inscripción fue realizada empleando la variante oriental del signario celtibérico ${ }^{15}$ (fig. 8).

morfo-etimológicos incontestables impiden pronunciarse sobre su carácter dual o su grado de coherencia», como indefinible con respecto al hecho de que su escritura hubiera aplicado o no el sistema dual para representar las consonantes oclusivas (Jordán 2004, pp. 285-286, y Jordán 2007, p. 133).

${ }^{12}$ Este estilo en la dirección de la escritura también se da en otras inscripciones celtibéricas como en el sello de Contrebia Belaisca (Botorrita, K.1.7), la fusayola de Arcobriga (Monreal de Ariza, K.7.1), la tésera de hospitalidad de Sasamón (Burgos, K.14.1) y otra de La Custodia (K.18.3). Cf. Untermann 1997, pp. 609-610, 658-659, 687-688 y 699-700.

${ }^{13}$ Cada uno de los puntos de estas interpunciones está formado por uno o dos triángulos superpuestos en forma de estrella, al estilo de los que encontramos en la tésera de la colección Fröhner (K.0.2) y en las inscripciones de las dos caras del broche de cinturón (K.1.2), que se supone que, como esta tésera, también procede de Contrebia Belaisca (Botorrita). Cf. Untermann 1997, pp. 283-284 y 574-576, y también considerado por Olcoz y Medrano e. p.

${ }^{14}$ Aunque con ciertas reservas, Gorrochategui 1990, p. 295, ya había propuesto la posible identificación de ke, como expresión de filiación «conocida en textos más diáfanos que éste».

15 Ya que si hubiera sido escrita empleando la representación gráfica de las consonates nasales característica de la región occidental de Celtiberia nos conduciría a una lectura que no permitiría relacionar al supuesto tekomiko con nada más y que, por tanto, llevaría a un posible callejón sin salida. Por otra parte, podemos clasificar la escritura de esta tésera de hospitalidad como incoherente con respecto al uso del sistema dual de representación gráfica para las consonantes oclusivas. Lo cual es consistente con que así sea en la mayoría de las inscripciones celtibéricas realizadas en la variante oriental del celtibérico, tal y como ya avanzó Jordán 2007, pp. 133 y 136-139, aunque no en lo que respecta a este texto en concreto. 
Aun sin pretender realizar un análisis lingüístico de la inscripción, y siguiendo la propuesta de Untermann, loukio se podría considerar el genitivo singular del antropónimo loukios ${ }^{16}$. Además, creemos que por simple semejanza con el contenido de los otros textos celtibéricos breves en los que aparece expresa la filiación en su fórmula onomástica celtibérica, el texto de esta tésera de hospitalidad se debe incluir entre ellos y se podría interpretar como 'De Tekonikos hijo de Loukios'. En el supuesto de que, además, se considere que tekonikos también es un antropónimo que figura en genitivo singular.

También cabe señalar que en el tercer bronce de Botorrita $\left(\right.$ K.1. $\left..3^{17}\right)$ figura un antropónimo tekos asociado en la misma línea al genitivo plural del pueblo de los $\operatorname{Konikos~}^{18}$. Aunque konikum, por cierto, también figura poco más adelante aunque asociado a otro antropónimo distinto: uirok $u^{19}$. Por lo que puede que los especialistas en lingüística indoeuropea, desde una perspectiva que excede el ámbito de la pura revisión paleográfica como la que aquí hemos presentado, estudien paralelos lingüísticos que arrojen más luz sobre el contenido del texto de esta tésera de hospitalidad y amplíen la información actual para el mejor conocimiento del carácter histórico y arqueológico del yacimiento de La Custodia, en particular, y de la cultura celtibérica y del complejo proceso de la romanización de la Península Ibérica, en general.

\section{Revisión y lectura completa de la inscripción K.12.1}

La incompleta lectura de esta estela, cuya inscripción también fue realizada mediante la técnica de incisión continua y que está fechada en la primera

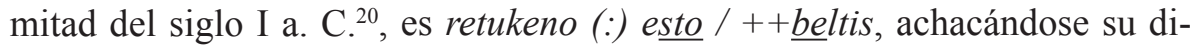
fícil lectura a que podría tratarse del posible fragmento de una lápida ${ }^{21}$. Sin

${ }^{16}$ Beltrán, De Hoz y Untermann 1996, p. 147, Untermann 1997, p. 699, y Untermann 2000, pp. 126 y 138.

17 Untermann 1997, pp. 576-606.

${ }^{18}$ II-49, tekos : konikum.

${ }^{19}$ III-26, uiroku : konikum.

${ }^{20}$ Jimeno en el siglo I a. C., por tanto, en la primera mitad de este siglo ya que, como hemos visto, después la ciudad fue abandonada. Jimeno 2005, p. 558.

${ }^{21}$ Jordán 2004, pp. 230-231, y 2007, p. 112, propuso que retukeno correspondía al antropónimo latino RECTVGENVS, de modo que esta inscripción apuntaría a ser coherente con el 
embargo, creemos que la suposición acerca de la falta de parte del objeto y, por tanto, de la inscripción, que también se había achacado a la tésera de hospitalidad de La Custodia que acabamos de comentar, era una hipótesis completamente errónea. De hecho, creemos que lo que ocurre es que en ambos casos no se tuvo en cuenta la correcta dirección en que fue realizada la escritura: en espiral, girando alrededor del borde del objeto. Aunque, en esta ocasión, se trata de dos líneas escritas en espiral pero cada una girando en un sentido opuesto al otro. De modo que el texto resultante, aunque aparece desordenado, también se corresponde con la misma fórmula onomástica celtibérica, siendo su lectura completa retukeno (:) ke (.) / beltistos (fig. 9).

BELTISTOS significa en griego clásico 'el más fuerte" ${ }^{22}$ por lo que, de confirmarse esta etimología, estaríamos ante un antropónimo griego o, al menos, indoeuropeo, adoptado por un celtíbero y, aunque la inscripción fue escrita en la variante occidental del celtibérico, que es en la que se han encontrado más textos realizados con un sistema de escritura coherente con la posible representación dual de las consonantes oclusivas ${ }^{23}$, debemos constatar que éste no es uno de estos casos debido al anómalo uso del alógrafo empleado para $t i$. A no ser que estemos ante una variante celtibérica del citado antropónimo cuya lectura fuera Beldistos, valoración ésta que queda a la espera de ser realizada por expertos en lingüística.

No obstante y, de nuevo, sin pretender llevar a cabo un análisis lingüístico de la inscripción, podemos aventurar que su significado podría ser 'Beltistos hijo de Retugenos', lo que sería coherente con que la función de la estela fuera puramente conmemorativa $\mathrm{y}$, concretamente, de carácter funerario.

\section{Revisión y lectura completa de la inscripción CD-1}

La lectura que propuso el editor de esta inscripción fue kamasiosue / ikenion ke / setantunos. Para la primera palabra propuso identificar un antropónimo

sistema de escritura dual. Aunque también señaló que si éste se supone que también afectaba al resto del texto, estaríamos ante el único caso de silabograma simple para la secuencia de consonante dental más $\mathrm{i}, t i$, de sólo dos segmentos superiores en vez de tres y que, además, debería leerse di, quedando: retugeno (:) esto / ++beldis o keldis.

${ }^{22}$ Lehmann 1993, p. 156.

${ }^{23}$ Jordán 2005, pp. 1013-1030 y Jordán 2007, p. 138. 
en dativo singular, kamasios, que consideró como inédito hasta entonces ${ }^{24}$ así como mejor alternativa al genitivo singular de otro kamas e isouei en dativo singular, que también serían sendos hápax. Para ikenion como la abreviatura de ikenion(ikum), en la que veía cierto parecido con el grupo familiar IGANCO, que está atestiguado en Clunia (Peñalba de Castro-Coruña del Conde, Burgos), a la que seguía ke, como abreviatura de kentis y con el significado de 'hijo de' que, a pesar de estar en orden inverso al característico de la onomástica celtibérica, afectaría al antropónimo setantunos, como genitivo singular del hápax setantu que, a su vez, podría estar relacionado con SEDATVS, a no ser que ke fuera una inédita abreviatura de $k a r^{25}$. Dudosa e incompleta lectura que fue muy discutida, por ejemplo, por Jordán y por Rubio, aunque tampoco acabaron de resolverla correctamente ${ }^{26}$.

Sin embargo, en esta ocasión creemos que la dirección de escritura no fue espiral, sino principalmente dextrógira y que el texto está distribuido en tres líneas que, a su vez, contienen cuatro palabras. Con la particularidad de que la segunda palabra empieza en la primera línea pero acaba en la segunda y la cuarta palabra vuelve a encontrarse en la segunda línea, continuando en espiral y, por tanto, de forma ortogonal al texto que ya había en ella, proponiendo como su lectura kamasios uen / ikenion / setantunos / $k e^{27}$ (fig. 10).

${ }^{24}$ Sin embargo, Villar y Prósper 2005, p. 174, que también hicieron su propia lectura y segmentación del texto de esta tésera de hospitalidad, citaron kamasio como «(antropónimo en gen. sg., cf. el capítulo III), que con toda probabilidad es idéntico al galo CAMASIVS (CIL XII, 1953, Drôme)».

${ }^{25}$ A pesar de la posible relación con el latino SEDATVS que propuso Faria 1998, pp. 120121, cabe señalar que Jordán 2001, pp. 374-375, propuso relacionarlo con Setantón. Como recogieron Villar y Prósper 2005, p. 213.

26 Jordán 2001, pp. 372-375, Rubio 2003, Jordán 2004, pp. 280-282, Villar y Prósper 2005, p. 213, y Jordán 2007, p. 118.

${ }^{27}$ Agradecemos a Javier de Hoz que tuviera la amabilidad de revisar el borrador de este trabajo y que nos aportara la corrección de la interpretación inicial que habíamos hecho de este texto como kamasios ue / ikenion / setantunos / $\mathrm{ka} / \mathrm{z}$, reconociéndole la autoría de la lectura definitiva que hemos presentado tras recibir su comentario que transcribimos a continuación: «En CD-1 hay cosas interesantes pero el supuesto topónimo final me parece lingüísticamente imposible y paleográficamente mejorable. Por falta de espacio al final de la primera línea el grabador escribió ya sobre la rotura antigua " $n$ ". La idea de ver en ue el comienzo de una segunda palabra me parece excelente, pero esa palabra sería uenikenion. La base "veni-" está bien documentada (vid. el Atlas de Untermann y el libro de Vallejo); el problema es que si se tratase de una abreviatura tendríamos demasiados sufijos. La interpretación que me parece 


\section{Tipología y distribución geográfica de las inscripciones con filiación expresa en su fórmula onomástica celtibérica}

Las tres inscripciones cuya lectura hemos completado pertenecen al pequeño conjunto de las que expresan explícitamente la filiación de su fórmula onomástica celtibérica en sus textos, que ahora está integrado por, al menos, nueve: siete que fueron realizadas en signario paleohispánico: K.0.2, K.12.1, K.16.1, K.17.1, K.18.2, CT-23A y CD-1, y dos que fueron escritas usando el alfabeto latino: K.3.14 y K.26.128.

La función y el tipo de objeto en el que fueron realizadas estas inscripciones corresponden a una tipología muy variada, así como también es muy dispersa su distribución geográfica (fig. 11).

Entre las seis inscripciones escritas en signario paleohispánico hay cuatro téseras de hospitalidad, de las cuales tres fueron escritas en la variante oriental del celtibérico y sólo una en la occidental, K.0.2 ${ }^{29}$, K.18.2, CD-1 y CT-

más económica no sería aceptable para la mayoría de mis colegas y es efectivamente muy hipotética, pero no veo otra salida; sería un genitivo de plural con conservación arcaizante de $/ o /$ sin pasar a $/ u /$ y evolución moderna de la nasal labial a dental, es decir rasgos contradictorios pero abundantes en las fórmulas onomásticas en epigrafía latina (en el libro de M. ${ }^{a}$ C. González, 1986, p. 141 ss.). En cuanto a la tercera línea, parece que tras el nombre en genitivo al grabador le faltó espacio y escribió el último signo encima del final de línea, como ocurre en un caso en Botorrita 1; el signo me parece claramente ke en su posición regular. En resumen, una fórmula clara: kamasios uen / ikenion / setantunos / ke 'Camasios, del grupo familiar de los Uenikenios, hijo de Setantu'».

${ }^{28}$ Nuevamente, sin contar con la citada posibilidad de que esta relación también pueda figurar en el primer bronce de Contrebia Belaisca (K.1.1), etc.

${ }^{29} \mathrm{La}$ lectura de esta inscripción es lubos (:) alizo / kum (:) aualo (:) ke (.) / kontebiaz / belaiskaz (.). Untermann 1967, pp. 281-288 (cf. 1997, pp. 539-540), interpretó la última palabra de esta inscripción como el origo de lubos, como después mantuvieron De Hoz y Beltrán (De Hoz 1986, pp. 70-71, y Beltrán 2001, p. 49, Beltrán 2004, pp. 51 y 54-55), hasta que este último planteó la posibilidad de que no fuera así y que correspondiera a la segunda parte de un pacto bilateral entre un individuo y una ciudad. Propuesta que después fue desarrollada por Jordán 2003, pp. 120-122 y pp. 96 y 265-267, y que parece que aunque convenció a Beltrán (2004), éste todavía mantuvo la viabilidad de la primera interpretación como alternativa posible. Sin embargo, Jordán 2007, p. 115, y 2008, p. 123, la ha mantenido e incluso aplicado a la interpretación de la tésera de Caminreal, cuya lectura es lazuro (:) Kosokum (:) Tarmestutez (:) Kar y que junto con su propuesta de relacionar Tarmestutez con la ceca Tarmeskom, leída antes como Bormeskom, le condujo a localizar ambas en Termes (Montejo de Tiermes, Soria), cf. Vicente y Ezquerra 2003, pp. 262 y 264-265. Aunque, respecto a esto último también tenemos nuestras dudas, sin que por ello nos decantemos 
23A, respectivamente (figs. 1, 7, 8 y 10). Tres de éstas son de origen desconocido, K.0.2, CT-23A y CD-1, aunque esta última podría proceder de Viana, como K.18.2, y la primera se supone que procedía de Contrebia Belaisca o, al menos del valle del río Jalón o del Huerva. También hay dos lápidas funerarias, K.12.1 y K.16.1 $1^{30}$, una escrita en la variante occidental del celtibérico y que procede de Langa de Duero y la otra hallada en Ibiza (Baleares), cuyo estilo de escritura y contenido también están relacionados con el valle del Jalón (figs. 9 y 2); así como un plato de bronce dedicado que, aunque por su estilo de escritura parece que procedía de la región oriental de Celtiberia, fue hallado en el pecio de un barco que naufragó en Gruissan, puerto romano de Narbona, K.17.1 $1^{31}$ (fig. 3).

Mientras que las dos inscripciones realizadas en alfabeto latino corresponden tanto a un grafito que se hallaba en la pared rocosa del santuario rupestre de la turolense Peñalba de Villastar, K.3.1432 (fig. 4), como a la dedicatoria

a favor o en contra de considerar que la referencia a la población en las citadas téseras de hospitalidad sea parte de la onomástica celtibérica de quien otorgó dicho pacto, posibilidad que también recogió Velaza 1999, p. 671, achacándola a «una imitación de los hábitos romanos y una cierta ostentación del prestigio que suponía pertenecer a una ciudad o comunidad determinada», o si se trata del que con éste hizo dicha población. También considerado por Olcoz y Medrano, e. p.

${ }^{30}$ La lectura de esta inscripción es tirtanos / abulokum / letontun / os ke beli/ kios, hallada por un vecino mientras realizaba labores agrícolas, en 1946. Cf. Mañá 1948, p. 477, García Bellido 1948, Gómez 1949, p. 330, y Jordán 2007, p. 121.

${ }^{31}$ La lectura de esta inscripción que dio Untermann 1977, p. 13, era ]ikum (:) steniotes (:) ke (:) rita, aunque se puede corregir por ]likum (:) steniotes (:) ke (:) rita, donde cabe la posibilidad de que la primera $l$ pudiera tratarse también de una $u$ y que, en cualquier caso y antes de este signo, hubiera una $o$, lo que llevaría a la lectura ]olikum, u otro signo cuya lectura parcial junto a la pérdida de los del comienzo de esta palabra impiden conocer de qué grupo familiar se trata. El texto parece que mantiene la fórmula de la onomástica celtibérica, tratándose de un miembro de un grupo familiar que era hijo de steniotes, pero como no se conoce el caso nominativo concreto al que corresponde el genitivo de este antropónimo y tampoco hay consenso acerca de si la última palabra hace referencia al origo o si pudiera tratarse del nombre del utensilio, el plato, o incluso de un verbo, como también dudan los lingüistas al tratar acerca de la inscripción K.26.1 y la relación de ésta con otras inscripciones, no es posible decir nada más. Siles 1985, Dellong 2003, p. 546, Jordán 2004, pp. 222-223, y 2007, pp. 126-127.

32 La lectura dada por Untermann 1977, pp. 13-15, también recogida por Jordán 2004,

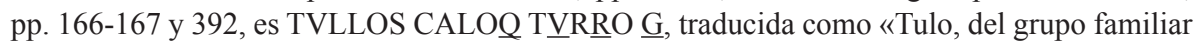
de los Calocos, hijo de Turro». Cf. Cabré 1910. 
existente en un sillar que fue hallada en Iuliobriga (Retortillo-Campoo de Enmedio, Cantabria), K.26.133 (fig. 5).

\section{Conclusiones}

Esperamos que la revisión y nueva lectura completa de los textos que hemos comentado sea de utilidad para los lingüistas y que, tras su correspondiente análisis, quizá, aporten información que también sea relevante para interpretar mejor los propios textos, la fórmula o fórmulas de la onomástica celtibérica en general y, concretamente, la variante en la que se menciona expresamente la filiación en su fórmula onomástica celtibérica, así como el contexto histórico y arqueológico de los yacimientos en los que estos objetos fueron encontrados.

\section{Agradecimientos}

Debemos reiterar nuestro agradecimiento a Francisco Beltrán por facilitarnos las fotografías de la tésera Fröhner que se halla en la Biblioteca Nacional de Francia (París) (fig. 1), cuya propuesta de revisión hemos presentado recientemente; a Jordi Hernando Fernández y al Museo Arqueológico de Puig des Molins (Ibiza) por la fotografía de la estela funeraria (n. ${ }^{\circ}$ 4967) (fig. 2); a Dominique Moulis y al Museo Arqueológico de Narbona (Aude, Languedoc-Roussillon, Francia) por las fotografías del plato de Gruissan (fig. 3); a Josep M. ${ }^{a}$ Bonet Girona y al Museo Arqueoló-

${ }^{33}$ La lectura de esta inscripción es ]LIC VIAMI / G. MONIM / AM. Aunque Untermann relacionó este texto con las otras inscripciones en cuestión, Jordán recopilando y exponiendo las distintas hipótesis planteadas acerca de él, recordó que todavía no estaba clara ni su posible interpretación ni incluso si la lengua celta en la que fue escrito fue celtibérico u otra. No obstante, relacionó esta inscripción con las de las páteras, cazos o trullae de plata procedentes del yacimiento arqueológico de Termes, que están en paradero desconocido pero cuyas lecturas son STENIONTE DOCILICO / AN GENTE MONIMAM y COVGIO VISCI / CO MONIMAM, K.11.1 (Untermann 1997, pp. 676-679 y 714-716, y Jordán 2004, pp. 360-362) y K.11.2, respectivamente, que Fita 1892, pp. 148-149 (y cf. Pujol 1886, p. 249), dató en el siglo I a. C., quizá «del tiempo de Sertorio o de Julio César». Por nuestra parte, nos habíamos limitado a plantear la posibilidad de que la presencia en Iuliobriga estuviera relacionada con el contexto histórico de las guerras cántabras o con sus consecuencias, sin explorar siquiera su posible análisis lingüístico (Olcoz y Medrano 2005-2007, pp. 205-206, cf. García Bellido 1956, pp. 170-171, e Iglesias 1976, p. 262). También hemos decidido incluir la ubicación de Tiermes en el mapa de la figura 10. 
gico de Cataluña (Barcelona) por la fotografía de la inscripción rupestre procedente de Peñalba de Villastar (Teruel) (fig. 4); a Raúl Gutiérrez Rodríguez y al Museo de Prehistoria y Arqueología de Cantabria por la fotografía adjunta correspondiente a la inscripción hispanocelta o celtibérica (n. ${ }^{\circ}$ 12396) (fig. 5); a Francisco Javier Zubiaur por las facilidades para el estudio así como por la cesión de las fotografías del Museo de Navarra (n. ${ }^{\circ}$ 6107), Pamplona, que adjuntamos (fig. 6); a Jesús Sesma por las oportunidades ofrecidas para poder completar este trabajo y por las fotografías que nos facilitó el Museo de Navarra (n. ${ }^{\circ}$ 6108) para el estudio de la inscripción K.18.2 (fig. 8); a Elías Terés, Marian Arlegui y al Museo Numantino (Soria), por las facilidades ofrecidas para el estudio de la estela con la inscripción K.12.1 (n. ${ }^{\circ}$ C860) (fig. 9); a Antonio José Marques de Faria que nos facilitara las fotografías de la tésera de hospitalidad que perteneció a la colección del anticuario Rainer Daehnhardt (fig. 10).

\section{BiBLIOGRAFÍA}

Almagro Gorbea, M. 2003: Epigrafia Prerromana, Catálogo del Gabinete de Antigüedades, I.1.1, Madrid.

Armendáriz Martija, J. 1997-1998: «El yacimiento arqueológico de La Custodia (Viana): triste trayectoria de una ciudad berona excepcional», Trabajos de Arqueología Navarra 13, Pamplona, pp. 7-32.

Ballester Gómez, X. 2004: «Notas a epígrafes celtibéricas de colecciones particulares», Paleohispánica 4, Zaragoza, pp. 265-282.

Beltrán Lloris, F. 2001: «La hospitalidad celtibérica: una aproximación desde la epigrafía latina», Paleohispánica 1, Zaragoza, pp. 35-62.

Beltrán Lloris, F. 2004: «De nuevo sobre la Tésera Froehner», Paleohispánica 4, Zaragoza, pp. 45-65.

Beltrán Lloris, F., Hoz Bravo, J. de y Untermann, J. 1996: El tercer bronce de Botorrita (Contrebia Belaisca), Zaragoza.

Burillo Mozota, F. 1995: «Celtiberia: monedas, ciudades y territorios», en García Bellido, M. P. y Sobral Centeno, R. M. (eds.), La moneda hispánica. Ciudad y territorio, Anejos de Archivo Español de Arqueología 14, Madrid, pp. 161-177.

Cabré Aguiló, J. 1910: «La montaña escrita de Peñalba», Boletín de la Real Academia de la Historia 56, Madrid, pp. 241-280.

Cabré Aguiló, J. 1944: Cerámica de Azaila: Museos Arqueológicos de Madrid, Barcelona y Zaragoza, Corpus Vasorum Hispanorum 56, Madrid.

Castiella Rodríguez, A. 1976: «Estratigrafía en el Poblado de la Edad del Hierro de "La Custodia", Viana (Navarra)», Anexo II, en Labeaga Mendiola, J. C., Carta arqueológica del término municipal de Viana (Navarra), Pamplona, pp. 231259. 
Dellong, E. 2003: Carte Archéologique de la Gaule 11/1. Narbonne et le Narbonnais, París.

Faria, A. J. 1998: «Duas novas tésseras celtibéricas de procedência desconhecida», Faventia 1, 2, Lisboa, pp. 119-122.

Fita Colomé, F. 1892, «Antigüedades Romanas», Boletín de la Real Academia de la Historia 21, Madrid, pp. 129-150.

García Bellido, A. 1948: «Inscripción Ibérica de Ibiza», Archivo Español de Arqueología 21, 72, Madrid, pp. 284-285.

García Bellido, A. 1956: «Excavaciones en Iuliobriga y Exploraciones en Cantabria. II Relación: Camapañas de 1953 a 1956», Archivo Español de Arqueología 29, 93-94, Madrid, pp. 131-139 у 170-171.

García-Bellido, M. ${ }^{a}$ P. y Blázquez, C. 2001: Diccionario de cecas y pueblos hispánicos. II: Catálogo de cecas y pueblos, Madrid.

Gómez Moreno, M. 1949: Misceláneas: historia, arte, arqueología. I, Primera serie: la Antigüedad, Madrid.

González Rodríguez, M. ${ }^{\text {a } C ., ~ 1986: ~ L a s ~ u n i d a d e s ~ o r g a n i z a t i v a s ~ d e l ~ a ́ r e a ~ i n d o e u r o p e a ~}$ de Hispania, Anejos de Veleia, Series Minor 2, Vitoria.

Gorrochategui Churruca, J. M. ${ }^{\text {a }}$ 1990: «Consideraciones sobre la fórmula onomástica y la expresión del origen en algunos textos celtibéricos menores», en Villar, F. (ed.), Studia indogermanica et paleohispanica in honorem A. Tovar et L. Michelenea, Salamanca, pp. 291-312.

Hoz Bravo, J. J. de 1986: «La Epigrafía Celtibérica», en Epigrafía hispánica de época Romano-Republicana. Reunión sobre Epigrafía Hispánica de Época RomanoRepublicana (Zaragoza, 1-3 de diciembre de 1983), Zaragoza, pp. 43-102.

Iglesias Gil, J. M. 1976: Epigrafía cántabra: estereometría, decoración, onomástica, Santander.

Jimeno Martínez, A., Chaín González, A. y Torre Echávarri, J. I. de la (eds.), Celtíberos. Tras la estela de Numancia, Catálogo de la exposición del Museo Numantino de Soria.

Jordán Cólera, C. B. 2001: «Chronica Epigraphica Celtiberica I. Novedades en Epigrafía Celtibérica», Paleohispánica 1, Zaragoza, pp. 369-391.

Jordán Cólera, C. B. 2003: «Acerca del ablativo que aparece en las téseras de hospitalidad celtibéricas», Paleohispánica 3, Zaragoza, pp. 113-127.

Jordán Cólera, C. B. 2004: Celtibérico, Zaragoza.

Jordán Cólera, C. B. 2005: «¿Sistema dual de escritura en celtibérico?», Paleohispánica 5 = Acta Paleohispánica IX. Actas del IX Coloquio sobre Lenguas y Culturas Paleohispánicas (Barcelona, 20-24 de octubre de 2004), Barcelona, pp. 1013-1030.

Jordán Cólera, C. B. 2007: «Estudios sobre el sistema dual de escritura en epigrafía no monetal celtibérica», Paleohispánica 7, Zaragoza, pp. 101-142. 
Jordán Cólera, C. B. 2008: «Toponimia y etnonimia en leyendas monetales celtibéricas y vasconas», en García Alonso, J. L. (ed.), Celtic and other languages in Ancient Europe, Salamanca, pp. 119-132.

Labeaga Mendiola, J. C. 1987, «Amuletos mágicos y téseras de hospitalidad en los yacimientos arqueológicos de Viana», Primer Congreso General de Historia de Navarra (Pamplona, 1986), Príncipe de Viana. Anejo 7, Pamplona, pp. 453-463.

Labeaga Mendiola, J. C. 1999-2000: «El Poblado de La Custodia», Trabajos de arqueología Navarra 14, Pamplona, pp. 19-34.

Labeaga Mendiola, J. C. y Untermann, J. 1993-1994: «Las téseras del poblado prerromano de La Custodia, Viana (Navarra). Descripción, epigrafía y lingüística», Trabajos de arqueología Navarra 11, Pamplona, pp. 45-53.

Lehmann, W. Ph. 1993: Theoretical Bases of Indo-European Linguistics, LondresNueva York.

Mañá de Angulo, J. M. ${ }^{a}$ 1948: «Epigrafía ibérica en Ibiza. Interesante hallazgo arqueológico», Revista Ibiza 28, Ibiza, p. 477.

Olcoz Yanguas, S. y Medrano Marqués, M. M. 2006: «Tito Livio: Castra Aelia y el límite meridional del ager Vasconum, antes y después de Sertorio», en Galán Lorda, M, Larraza Micheltorena, M. ${ }^{\mathrm{a}}$ M. y Oslé Guerendiáin, L. E. (eds.), Navarra: Memoria e Imagen (I), VI Congreso de Historia de Navarra, Pamplona, pp. 55-75.

Olcoz Yanguas, S. y Medrano Marqués, M. M. a 2005-2007: «Inscripciones paleohispánicas, Turiaso, Uxama Argaela y las Guerras Cántabras», Turiaso 18, Tarazona, pp. 199-214.

Olcoz Yanguas, S. y Medrano Marqués, M. M. ${ }^{\text {a }}$ e. p.: «Revisión paleográfica de varias inscripciones celtibéricas de los valles del Jiloca y Huerva», Kalathos, Teruel, en prensa.

Prósper Pérez, B. M. ${ }^{\text {a } 2007: ~ E s t u d i o ~ L i n g u ̈ i ́ s t i c o ~ d e l ~ P l o m o ~ C e l t i b e ́ r i c o ~ d e ~ I n i e s t a, ~}$ Salamanca.

Prósper Pérez, B. M. ${ }^{\text {a } 2008: ~ E l ~ B r o n c e ~ C e l t i b e ́ r i c o ~ d e ~ B o t o r r i t a ~ I, ~ P i s a-R o m a . ~}$

Pujol Camps, C. 1886: «Noticias», Boletín de la Real Academia de la Historia 8, 4, Madrid, p. 249.

Rabal, N. 1888: «Una visita a las ruinas de Termancia», Boletín de la Real Academia de la Historia 13, 5, Madrid, pp. 451-471.

Rubio Orecilla, F. J. 2003: «Acerca de nuevas y viejas inscripciones», Paleohispánica 3, Zaragoza, pp. 141-161.

Siles Ruiz, J. 1985: «Las páteras, en caracteres latinos, de Tiermes y un plato de bronce, con inscripción celtibérica, encontrado en Gruissan», en Symbolae Ludovico Mitxelena Setuagenario Oblatae, Veleia. Anejos 1, Vitoria, pp. 455-462.

Tabernero Galán, C., Heras Fernández, E., Benito Batanero, J. P. y Sanz Aragonés, A. 2005: «Segontia Lanka», en Jimeno Martínez, Chaín González y De la Torre Echávarri (eds.), pp. 197-204. 
Taracena Aguirre, B. 1929: Excavaciones en las provincias de Soria y Logroño. Memoria de las excavaciones practicadas en 1928, Junta Superior de Excavaciones y Antigüedades, Memorias 103, Madrid.

Tovar Llorente, A. 1949: Estudios sobre las primitivas lenguas hispánicas, Buenos Aires.

Untermann, J. 1967: «Die Endung des Genitiv singularis der o-Stämme im Keltiberischen», en Meid, W. (ed.), Beitrage zur Indogermanistik und Keltologie, Julius Pokorny zum 80. Geburtstag gewidmet, Innsbrucker Beiträge zur Kulturwissenschaft 13, Wiesbaden, pp. 281-288.

Untermann, J. 1977: «En torno a las inscripciones rupestres de Peñalba de Villastar», Teruel 57-58, Teruel, pp. 5-22.

Untermann, J. 1997: Monumenta Linguarum Hispanicarum, Band IV. Die tartessichen, keltiberischen und lusitanischen Inschriften, Wiesbaden.

Untermann, J. 2000: «La terminación del genitivo singular de los temas en -o en el celtibérico: de 1965 a 1995», Estudios de Lenguas y Epigrafía Antiguas 3, Valencia, pp. 125-142.

Velaza Frías, J. 1989: «A propósito de las téseras de hospitalidad de Viana», Veleia 6, Vitoria, pp. 193-197.

Velaza Frías, J. 1999: «Balance actual de la onomástica personal celtibérica», en Villar, F. y Beltrán, F. (eds.), Pueblos, Lenguas y Escrituras en la Hispania Prerromana. Actas del VII Coloquio sobre Lenguas y Culturas Paleohispánicas, Salamanca, pp. 663-683.

Vicente Redón, J. D. y Ezquerra Lebrón, B. 2003: «La tésera de Lazuro: Un nuevo documento celtibérico en "La Caridad" (Caminreal, Teruel)», Paleohispánica 3, Zaragoza, pp. 251-269.

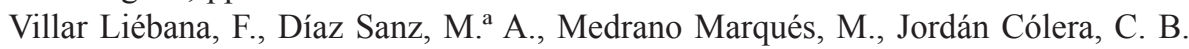
2001: El IV Bronce de Botorrita (Contrebia Belaisca): Arqueología y Lingüística, Salamanca.

Villar Liébana, F. y Prósper Pérez, B. M. a 2005: Vascos, Celtas e Indoeuropeos. Genes y Lenguas, Salamanca.

Fecha de recepción de la primera versión del artículo: 24/11/2009

Fecha de recepción de la versión definitiva del artículo: 26/04/2010

Fecha de aceptación: 22/04/2010 
ApÉNDICE DE IMÁGENES

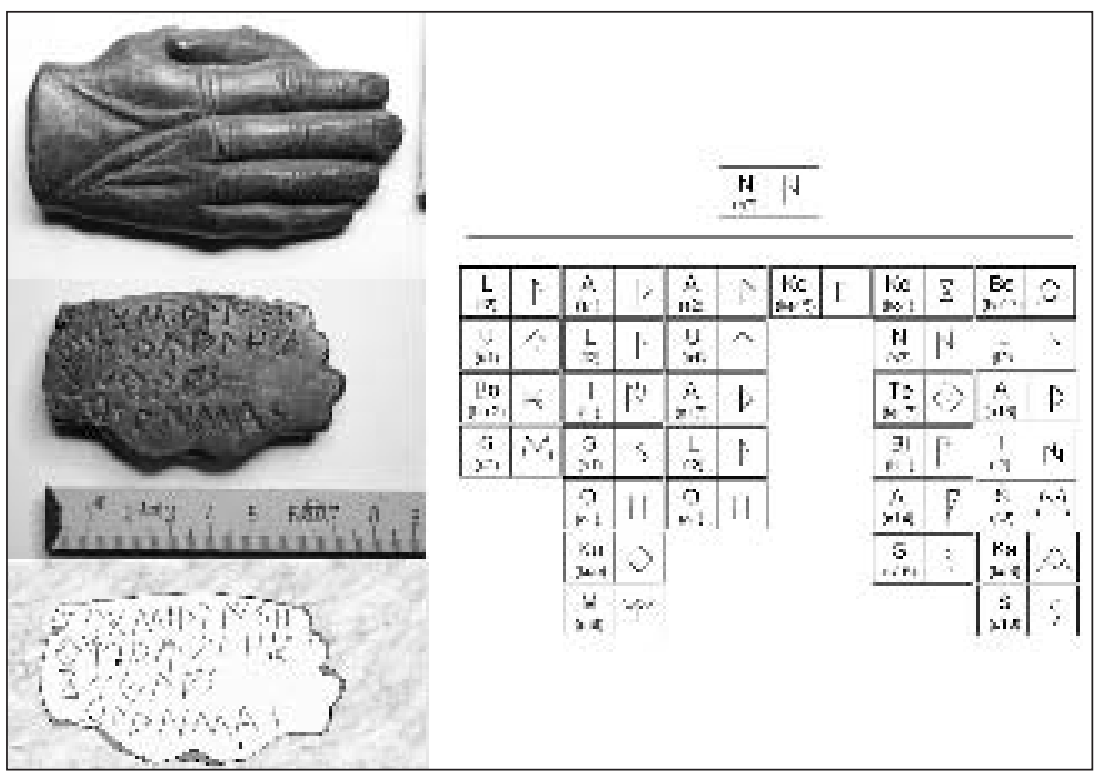

Figura 1

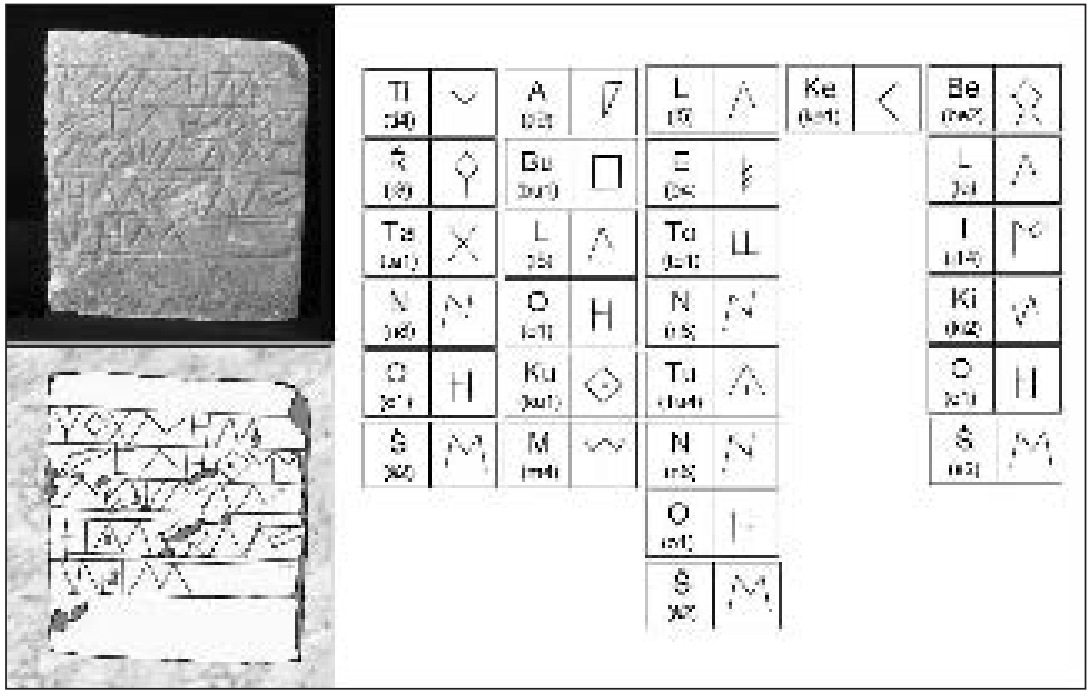

Figura 2 


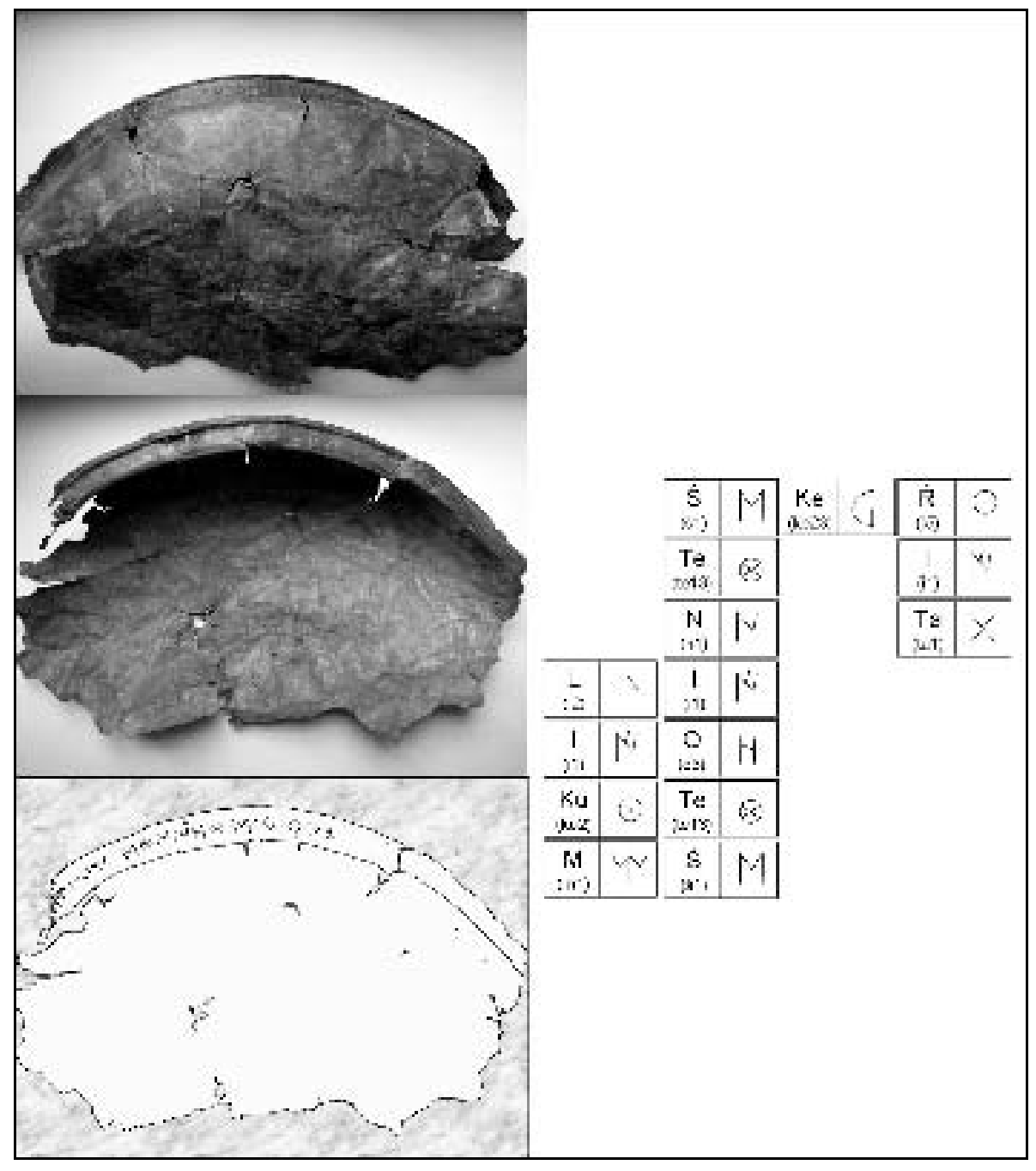

Figura 3 


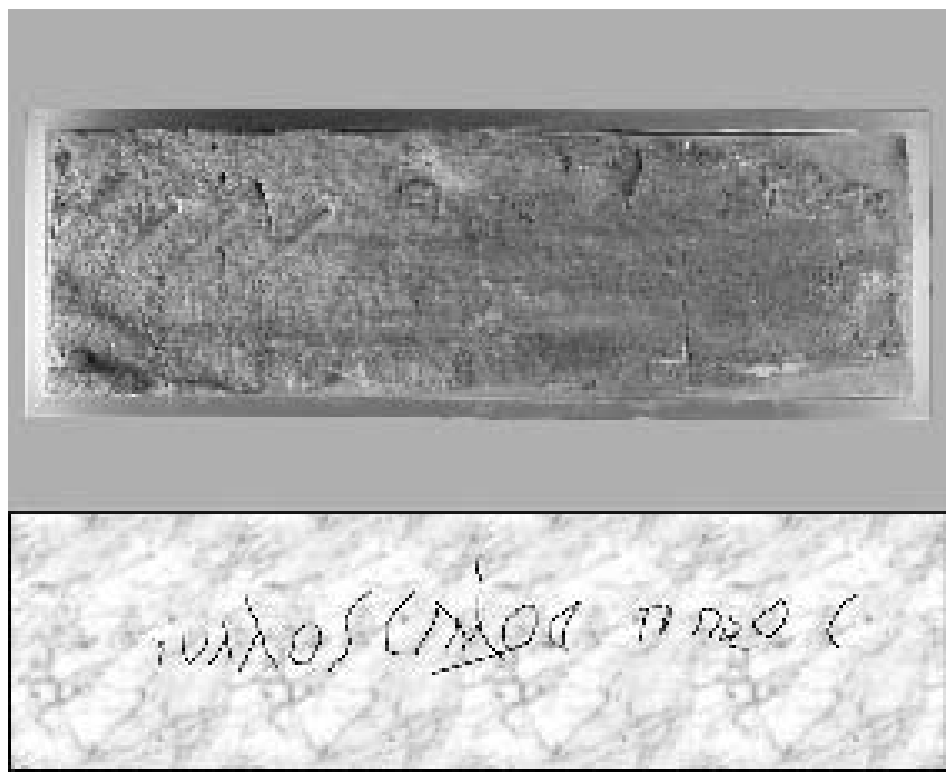

Figura 4

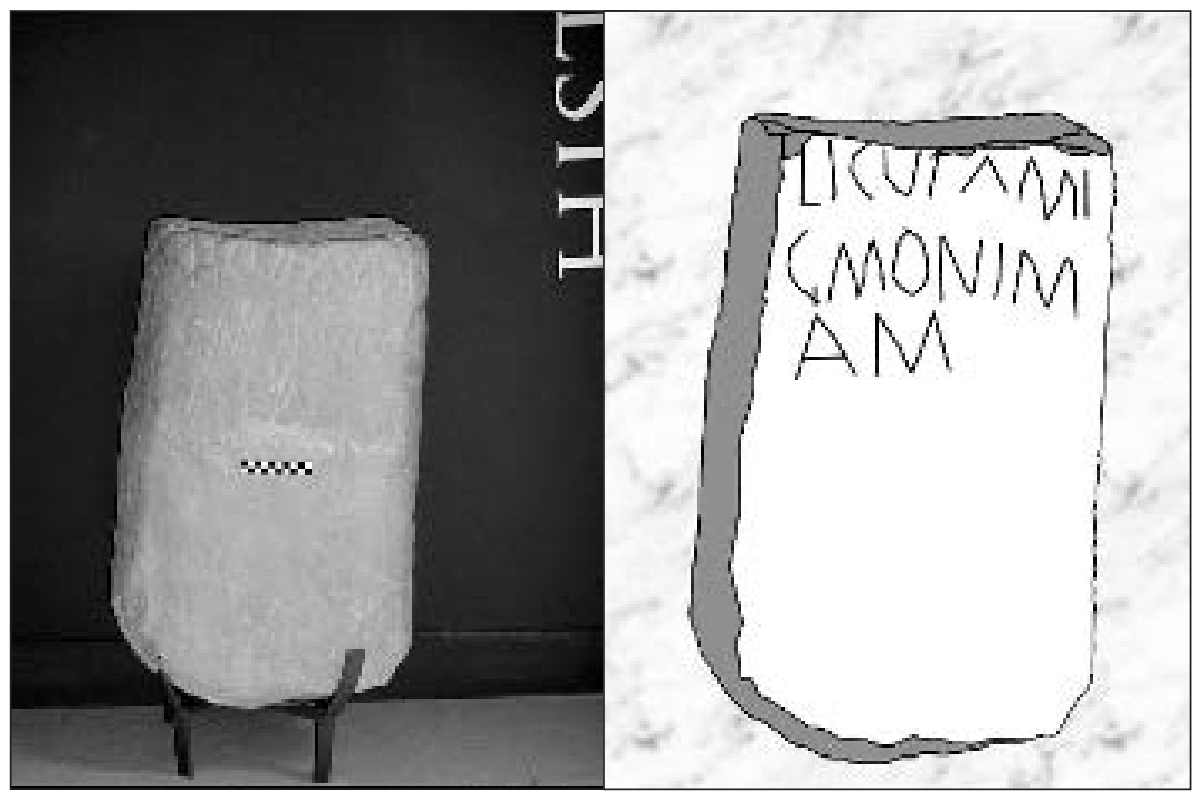

Figura 5 
INSCRIPCIONES CELTIBÉRICAS CON FÓRMULA DE FILIACIÓN 101

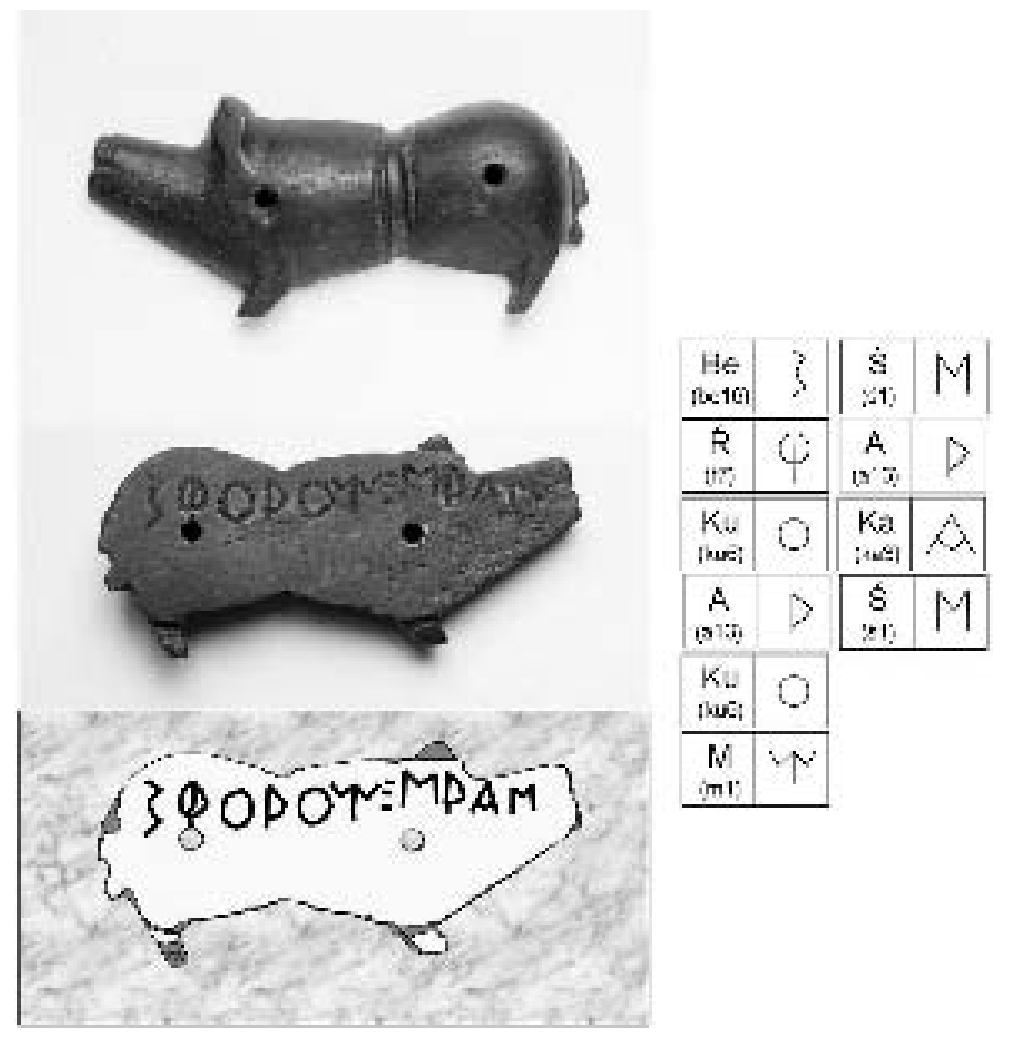

Figura 6
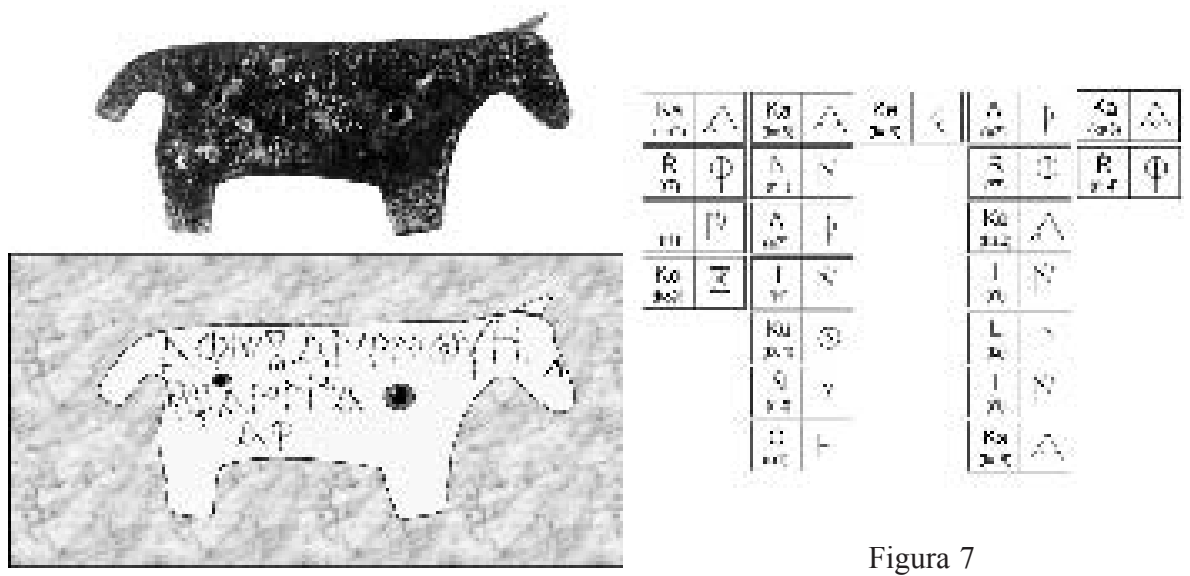

Figura 7 


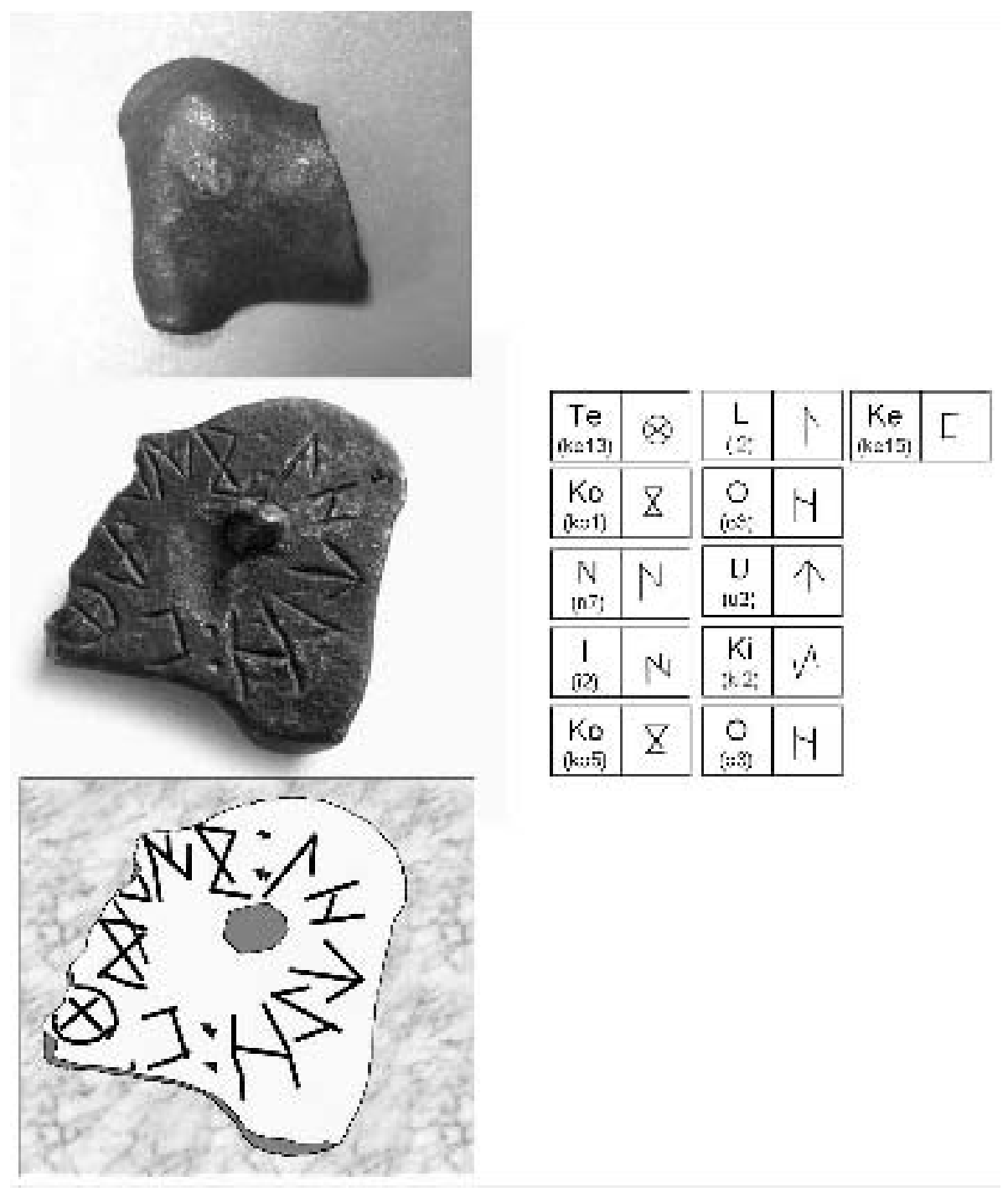

Figura 8 


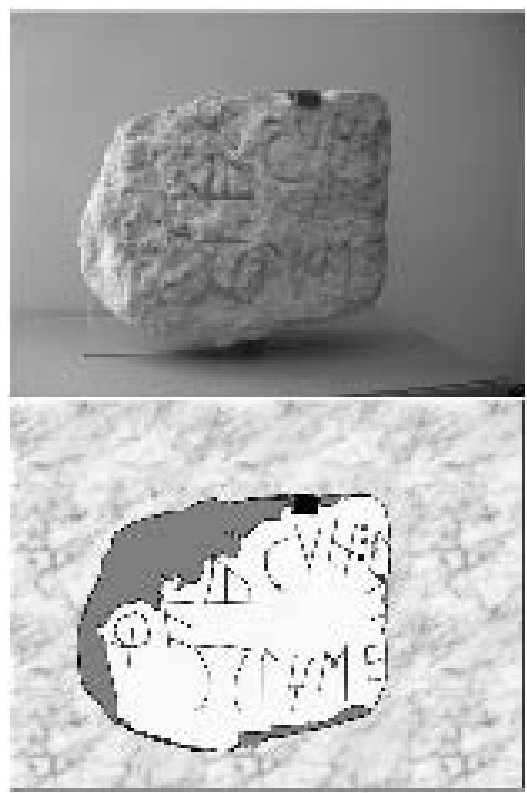

\begin{tabular}{|c|c|c|c|c|c|}
\hline $\begin{array}{l}R \\
\text { is }\end{array}$ & 4 & $\begin{array}{c}K \theta \\
\text { Kis } 21 \\
\end{array}$ & $E$ & $\begin{array}{c}B \in \\
\text { thesy }\end{array}$ & $\vdots$ \\
\hline$\underset{(00)}{E}$ & 8 & & & $\frac{\mathrm{L}}{\mathrm{j} z}$ & 1 \\
\hline $\begin{array}{c}\text { Tu } \\
\text { - }\end{array}$ & $\Delta$ & & & 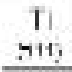 & 누 \\
\hline $\begin{array}{l}\mathrm{Ke} \\
\text { innil| }\end{array}$ & 6 & & & $\underset{|b| 1}{S}$ & 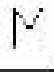 \\
\hline $\begin{array}{c}\text { रो } \\
\text { iin? }\end{array}$ & $y$ & & & $\begin{array}{l}\text { To } \\
\\
\end{array}$ & $\Perp$ \\
\hline$Q$ & $\mathrm{H}$ & & & $\begin{array}{r}5 \\
(a-1) \\
\end{array}$ & $1 \%$ \\
\hline
\end{tabular}

Figura 9

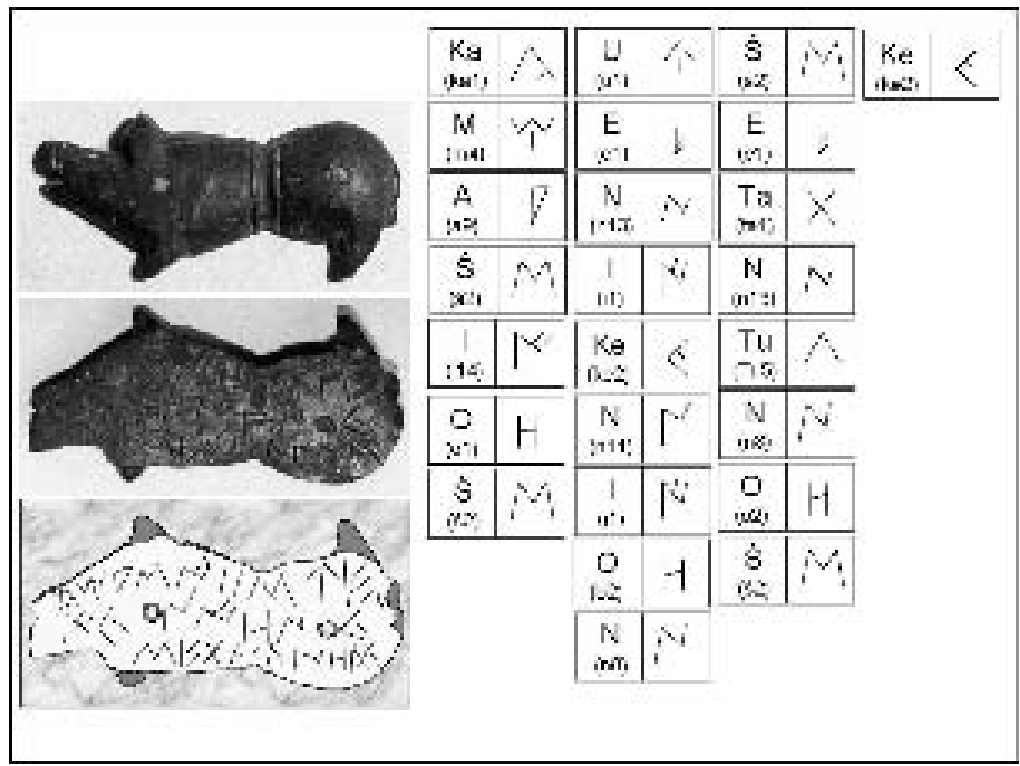

Figura 10 


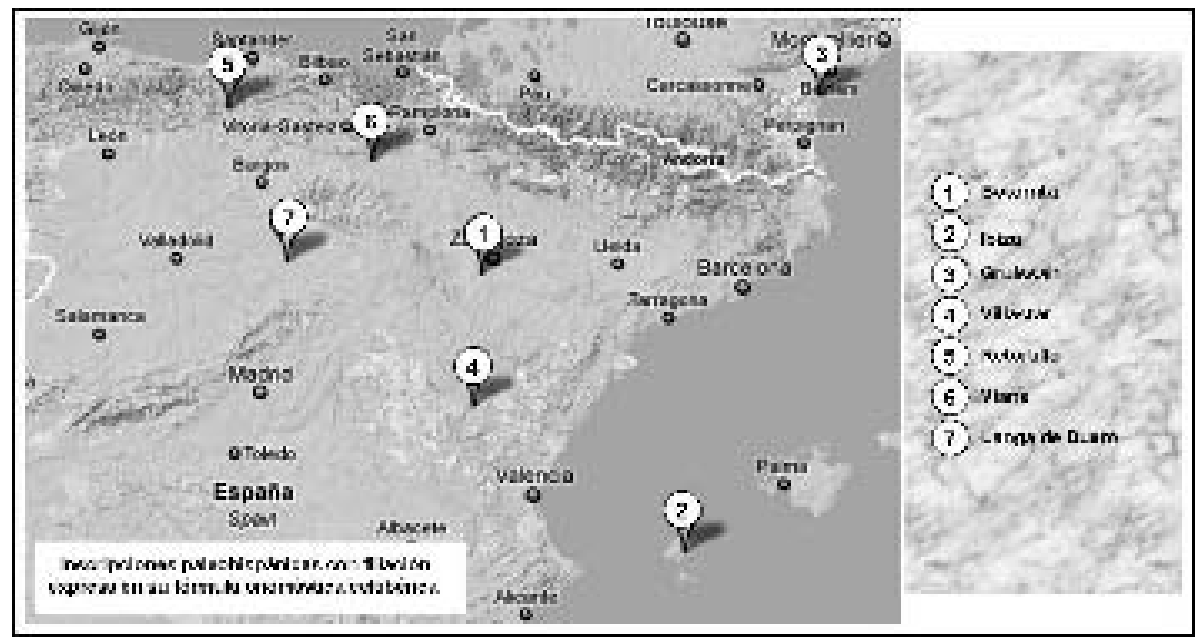

Figura 11 